\title{
Análise da Eficácia da Ferramenta Merchandising: Um estudo com Consumidores de Supermercados na Cidade de Assaré
}

\author{
Yasmin Ferreira Dias ${ }^{1}$; Gabriel José Andrade Oliveira ${ }^{2}$; Maria Patrícia de Alencar ${ }^{3}$; \\ Cristiano Viana Cavalcanti Castellão Tavares ${ }^{4}$
}

\begin{abstract}
Resumo: O corrente estudo propõe uma análise mais aprofundada a respeito do merchandising e a utilização de suas ferramentas como mecanismo para ampliar as vendas. A presente pesquisa tem como objetivo investigar a percepção dos clientes sobre as técnicas de merchandising aplicadas nos supermercados da cidade de Assaré - CE, e a influência dessas técnicas sobre os consumidores. Para alcançar o objetivo exposto, a pesquisa se caracteriza como exploratória descritiva e quantitativa. Foram aplicados questionários com perguntas fechadas aos consumidores dos supermercados da cidade em pesquisa, com a finalidade de obter respostas significativas que estão expostas na conclusão desta pesquisa. Contatou-se nessa pesquisa que para uma parcela significativa da população entrevistada, as técnicas de merchandising têm se mostrado eficientes, e que apesar de muitas vezes o potencial dessas técnicas não seja utilizado por completo, é possível notar o grau de influências que essas possuem sobre as decisões finais de compra dos consumidores.
\end{abstract}

Palavras Chave: Marketing. Merchandising. Ponto de Venda.

\section{Analysis of the Effectiveness of the Merchandising Tool: A study with Consumers of Supermarkets in Assaré City}

\begin{abstract}
The current study proposes a more in-depth analysis of merchandising and the use of its tools as a mechanism to increase sales. The present research aims to investigate the perception of customers about the techniques of merchandising applied in supermarkets in the city of Assare - CE, and the influence of these techniques on consumers. To achieve the goal, the research is characterized as exploratory descriptive and quantitative. Questionnaires with some specific questions were applied to the consumers of the city of these supermarkets in research, in order to obtain significant answers that are exposed at the conclusion of this research. It was found in this research that for a significant portion of the population interviewed, merchandising techniques have been efficient, and that although the potential of these techniques is often not fully used, it is possible to note the degree of influence they have on consumers' final purchasing decisions.
\end{abstract}

Keywords: Marketing. Merchandising. Sale Point.

\footnotetext{
${ }^{1}$ Bacharel em Administração pelo Centro Universitário Dr. Leão Sampaio/Unileão, diasyasmim@gmail.com

2 Bacharel em Administração pelo Centro Universitário Dr. Leão Sampaio/Unileão, gabrieloliveira.m12@ gmail.com

${ }^{3}$ Bacharel em Administração pelo Centro Universitário Dr. Leão Sampaio/Unileão, patriciaalencar133@ gmail.com

${ }^{4}$ Professor orientador do Centro Universitário Dr. Leão Sampaio/Unileão, Doutorando em Desenvolvimento Sustentável pela Universidade de Brasília (UNB), Mestre em Administração de Empresas pela Universidade Estadual do Ceará (UECE), Administrador na pró-reitoria de planejamento e orçamento da Universidade Federal do Cariri (UFCA),c.castellao@ gmail.com
} 


\section{Introdução}

Com a alta competitividade no mercado e o aumento constante da concorrência, a necessidade das marcas de se destacarem em meio à multidão vem crescendo e se tornando uma tendência. Com isso, cresce também a importância do marketing e principalmente do merchandising, como uma ferramenta capaz de diferenciar os produtos no ponto de venda, atraindo o olhar dos consumidores e influenciando no momento mais importante, que é no momento da decisão de compra.

A presente pesquisa busca investigar a percepção dos clientes sobre as técnicas de merchandising aplicadas em supermercados não especificados na cidade de Assaré - CE, e a influência dessas técnicas sobre os consumidores.

Uma vez que as empresas vêm aumentando expressivamente os seus investimentos em merchandising nos últimos anos, chegando a marca de quase $\mathrm{R} \$ 7$ bilhões gastos só na televisão no ano de 2015 de acordo com o Kantar IBOPE Media (2016), fora os gastos com merchandising em pontos-de-venda fixos, revelando-se assim como um dos principais investimentos publicitários no país, o que demonstra a importância dessa ferramenta nas estratégias de promoção.

Em face do exposto, é importante analisar qual é a eficácia desses investimentos, e quais os impactos provocados sobre os consumidores e colaboradores. Para tanto, inicialmente foi realizado um levantamento bibliográfico com o objetivo de fornecer aos pesquisadores um conhecimento mais aprofundado sobre o tema proposto, e em seguida, foi realizada uma pesquisa de cunho quantitativo para o levantamento de dados primários, buscando analisar a percepção dos clientes de supermercados a respeito das técnicas de merchandising.

\section{Marketing}

Existem na literatura vários autores com vários conceitos de marketing, apesar das citações estarem apresentadas com palavras diferentes, os conceitos entre os autores se assemelham e se convergem. De acordo com Las Casas (2006) marketing é uma palavra inglesa que significa ação no mercado ou mercado em movimento. Las Casas (2007) completa ainda, 
ao afirmar que o marketing é responsável por abranger todas as atividades referentes às relações de troca, que buscam satisfazer desejos e necessidades dos consumidores.

Convergindo com as ideais de Las Casas, segundo Rocha; Chirstensen (1999), o marketing é a função organizacional que procura adequar a oferta da empresa à demanda do mercado, utilizando-se de diversas ferramentas e técnicas. Para eles, o marketing tem ainda uma função social, que é atender as necessidades dos clientes.

Oliveira et al. (2007) dizem que o marketing está voltado totalmente para o consumidor, identificando e estimulando as necessidades e desejos dos clientes.

Para Memória (2010), o marketing se transformou em uma ferramenta estratégica para as organizações, facilitando para que estas conheçam melhor os seus produtos e serviços que são ofertados aos clientes, seus pontos fortes e fracos diante do mercado, e proporcionando as empresas um melhor planejamento estratégico para a venda de seus produtos ou serviços, a fim de superar a concorrência.

Segundo Kotler e Keller (2006) o marketing busca identificar e suprir as necessidades humanas e sociais dos consumidores de forma lucrativa para a empresa.

\section{Merchandising}

Segundo Las Casas (2009) enquanto o termo marketing se refere a ação no mercado, o termo merchandising se refere a ação na mercadoria, onde devem estar presentes todos os elementos que compõe o marketing.

Complementando a ideia apresentada por Las Casas (2009), para Oliveira et al. (2007) o merchandising é toda a ação que busca valorizar um produto, fazendo com que este se destaque da concorrência, influenciando o cliente na sua decisão final de compra.

Blessa (2008) concorda com Oliveira et al. (2007) ao dizer que o merchandising é toda e qualquer ação, técnica ou material promocional utilizado no ponto de venda para proporcionar informação e uma maior visibilidade para marcas, produtos e serviços.

Oliveira et al. (2007) contam que o merchandising surgiu devido ao nascimento dos estabelecimentos de autosserviço, para que as próprias embalagens dos produtos pudessem falar com os clientes. Para eles, o merchandising é fundamental para alavancar a demanda dos produtos, aumentando assim as vendas. 
Para Oliveira et al. (2007), o merchandising é considerado eficiente, pois sua comunicação acarreta a junção dos três principais elementos para que uma venda possa ocorrer, os quais são o consumidor, o produto e o dinheiro. Tem como atribuições básicas, elevar as vendas por impulso, gerar um elo de junção entre a propaganda e o produto nos pontos de vendas, chamar a atenção do consumidor, exibir o produto de forma mais atraente, trazer uma melhor promoção e identificação da marca ou produto, e como resultado, elevar a rentabilidade do negócio.

Las Casas (2009) afirma ainda que o merchandising é composto por diversas ações estratégicas que são postas em prática no ponto-de-venda com o objetivo de oferecer sempre o produto certo, no local certo, no tempo certo, na quantidade certa, com o preço adequado. Ainda conforme Las Casas (2009) por volta de $8 \%$ dos produtos que os clientes desejam comprar não estão disponíveis em estoque, enquanto que cerca de um terço dos produtos são vendidos a preços promocionais devido aos altos níveis de estoque.

De acordo com Las Casas (2009) constituem-se operações do merchandising:

- Exposição e apresentação dos produtos;

- Verificação dos níveis de estoque;

- Verificação dos preços;

- Verificação das datas de validade dos produtos;

- Treinamento adequado nos locais;

- Comunicação adequada nos locais;

- Atenção de área de vendas compatíveis;

- Verificação do estado do material no ponto de venda;

- Amostragem e demonstração de produtos no ponto-de-venda.

Bezerra e Viana (2013) afirmam que as operações do merchandising são aliados importantes tanto para os clientes quanto para as empresas, uma vez que estas buscam oferecer um ambiente que possua uma atmosfera agradável, contribuindo para que o cliente se sinta bem estando dentro do ambiente do negócio, e tornando a sua compra uma experiência agradável e prazerosa. Para Bezerra; Viana (2013), as ações do merchandising têm uma enorme importância, uma vez que estas são realizadas no momento em que ocorre a decisão ou não pela compra. Além disso, a percepção do consumidor a respeito das ações de merchandising ainda serve como indicador de satisfação em relação ao supermercado. 
Para Memória (2010), o merchandising em ponto-de-venda é um recurso de baixo custo que visa chamar a atenção do consumidor, despertando nestes o desejo e impulso de compra, utilizando-se de displays, preços destacados, ilhas de produtos, promoção de vendas, entre outras.

Bezerra e Viana (2013) concordam com Memória (2010) ao dizerem que os consumidores têm suas compras apenas parcialmente planejadas, sendo que geralmente a escolha da marca é feita apenas no ponto de venda, o que torna o merchandising indispensável.

Blessa (2005 apud MEMÓRIA, 2010) concorda com os autores antes citados, e afirma que o merchandising possui o papel essencial de despertar necessidades de compra antes inexistentes.

Xavier; Silva (2010) afirmam que o marketing em hipótese alguma deve deixar de lado o merchandising no ponto de venda, pois este é o último recurso que liga o cliente à empresa. Já para Oliveira et al. (2007), o merchandising é o próprio ponto de venda, e este por sua vez é responsável por criar um ambiente favorável à compra.

Oliveira et al. (2007) afirmam ainda que para que as ações de merchandising tenham sucesso, é necessário que haja a disposição de todas as áreas da empresa, como marketing, vendas e logística.

Costa; Crescitelli (2007 apud COSTA et al. 2014) concordam com os autores acima citados, apontam o merchandising como toda e qualquer ação que busca valorizar e enriquecer o produto no ponto de venda, com o objetivo de diferenciá-lo e destacá-lo da concorrência, influenciando o consumidor na decisão de compra.

\section{O Ramo de Supermercados no Brasil}

Segundo Oliveira et al. (2007) os supermercados constituem a essência do sistema de vendas do autosserviço. De acordo com o autor, o sistema de autosserviço desenvolveu-se a partir da combinação de mercearias, padarias e açougues, que resultaram nos supermercados.

Oliveira et al. (2007) descrevem o autosserviço como o sistema no qual o próprio cliente é responsável por entrar na loja, procurar o que deseja, e colocar no seu carrinho de compra, diferente dos sistemas tradicionais, onde haviam funcionários sempre disponíveis para atendêlo. 
Segundo pesquisa divulgada pela Associação Brasileira de Supermercados (ABRAS, 2016) o setor de supermercados em 2015 teve um crescimento nominal de 7,1\% se comparado a 2014, e um faturamento de $\mathrm{R} \$ 315,8$ bilhões. Atualmente, segundo a mesma pesquisa, o setor supermercadista já representa 5,4\% do PIB nacional, sendo composto por cerca de 84,5 mil lojas e mais de 1,847 milhão de funcionários. A pesquisa aponta ainda que o faturamento das 20 maiores empresas supermercadistas chegou a $\mathrm{R} \$ 201,7$ bilhões do total registrado em 2015.

\section{Metodologia}

A presente pesquisa é de natureza aplicada, uma vez que busca gerar conhecimentos sobre o uso de ferramentas do merchandising como forma de atrair e fidelizar clientes em supermercados. Segundo Mattar (2005) a pesquisa aplicada tem como principal objetivo gerar conhecimento para solucionar problemas práticos e específicos.

Quanto a sua forma de abordagem, a pesquisa caracteriza-se como quantitativa, uma vez que busca conhecer aspectos subjetivos sobre a percepção dos clientes a respeito das técnicas de merchandising, o impacto que estas técnicas têm sobre os clientes, e qual o retorno em número que podemos obter a partir da utilização correta das mesmas. Faria; Faria (2009) afirmam que a pesquisa quantitativa busca resultados através da comparação de números.

Inicialmente a pesquisa possui caráter exploratório, na medida em que busca fornecer ao pesquisador dados secundários sobre marketing, merchandising, e o ramo de supermercados no Brasil, proporcionando ao pesquisador maior familiaridade com o tema estudado. De acordo com Malhotra (2005) a pesquisa exploratória visa trazer um conhecimento e compreensão maiores sobre o assunto em estudo.

Posteriormente, o trabalho assume um objetivo de cunho descritivo, ao buscar se aprofundar nas técnicas de merchandising, e na sua utilização no ramo de supermercados, colocando no centro do estudo o impacto que estas técnicas têm sobre os consumidores, e como estas influenciam em sua decisão final de compra, buscando analisar a percepção dos mesmos. Para Malhotra (2005) a pesquisa descritiva é muito útil para descrever a percepção de usuários e o seu relacionamento com um determinado produto ou serviço.

Para o levantamento de dados primários, foram aplicados 136 questionários com pessoas na cidade de Assaré, através da técnica de amostragem não probabilística por cota e 
julgamento, com homens e mulheres, residentes na área urbana, chefes de família, ou que sejam responsáveis por realizar as compras de casa, de idade entre 20 e 69 anos. Para a quantificação da amostra foi utilizada uma população base de 6629 tendo como base o IBGE (2016) Censo Demográfico de 2010 e levando em consideração que cerca de $90 \%$ dessas pessoas vão ao supermercado. A pesquisa conta com um nível de confiança de $95 \%$ e erro amostral tolerável de 5\%. Conforme cálculo proposto por Santos (2016):

$$
n=\frac{N \cdot Z^{2} \cdot p \cdot(1-p)}{Z^{2} \cdot p \cdot(1-p)+e^{2} \cdot(N-1)}
$$

Como instrumento de coleta de dados foi utilizado roteiro estruturado através de entrevistas. Os dados dos clientes serão mantidos em sigilo. Malhotra (2005), explica que a amostra por julgamento busca abordar elementos que se acredita representar a população de interesse para o estudo. Será quantitativa com perguntas fechadas procurando explorar aspectos subjetivos e comportamento e influência da ferramenta nas compras.

Após realizadas as entrevistas e aplicados os questionários as informações foram tabuladas utilizando o software Microsoft Excel, e os dados apresentados através de gráficos e tabelas.

O presente projeto de pesquisa foi inicialmente submetido ao Comitê de Ética em Pesquisa (CEP) do Centro Universitário Doutor Leão Sampaio. Após a aprovação do Comitê de Ética foram abordados consumidores selecionados dos supermercados da cidade de Assaré - CE para responderem o questionário para a realização da investigação sobre o tema abordado.

Os participantes do estudo foram informados sobre os objetivos e a metodologia utilizada na pesquisa; foi assegurado aos participantes o sigilo, a confidencialidade das informações, assim como o direito de recusar-se a participar ou solicitar sua exclusão a qualquer momento do estudo, sem ter prejuízos de qualquer natureza.

Os clientes que aceitaram participar do estudo receberam duas cópias do Termo de Consentimento Livre e Esclarecido (TCLE), esses ficaram com uma via assinada pelos pesquisadores e devolveram a outra, ficando assim acordada a aceitação para participar da pesquisa, autorizando também a divulgação e publicação dos resultados da mesma. Após a assinatura do TCLE, os participantes responderam ao questionário que compõe a pesquisa. $\mathrm{O}$ 
presente estudo seguiu as determinações da resolução 466/12 do Conselho Nacional de Saúde (CNS) que normatiza as pesquisas com seres humanos.

\section{Análise e Discussão dos Resultados}

Neste tópico serão expostos os resultados obtidos em pesquisa realizada na cidade de Assaré - CE, com consumidores de supermercados, com o objetivo de analisar a opinião dos clientes a respeito das técnicas de merchandising aplicadas nesses estabelecimentos, e qual o grau de influência que essas técnicas têm sobre os consumidores.

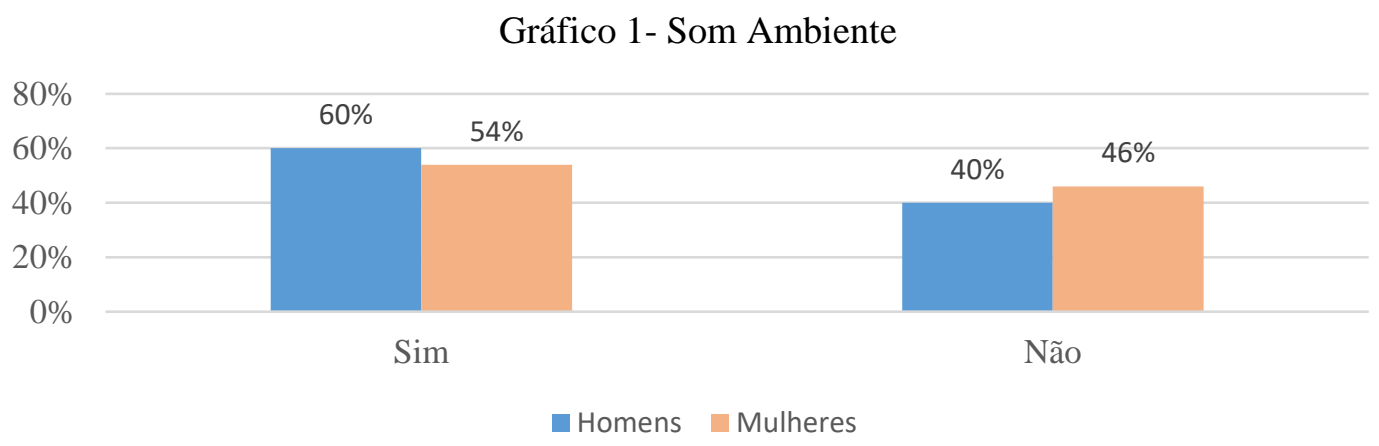

Fonte: Dados da Pesquisa (2016)

Constata-se no gráfico 1 que para 60\% dos homens e 54\% das mulheres, o som ambiente influencia na decisão de compra, enquanto que para $40 \%$ dos homens e $46 \%$ das mulheres, o som ambiente não tem influência sobre as decisões de compra. Com esse resultado reafirma-se o que foi dito por Bezerra; Viana (2013), que uma atmosfera de compra agradável acaba por incentivar e influenciar os clientes a passarem mais tempo no ponto de venda, e acabarem por consumirem mais. 
Gráfico 2- Som Ambiente: Grau de Influência

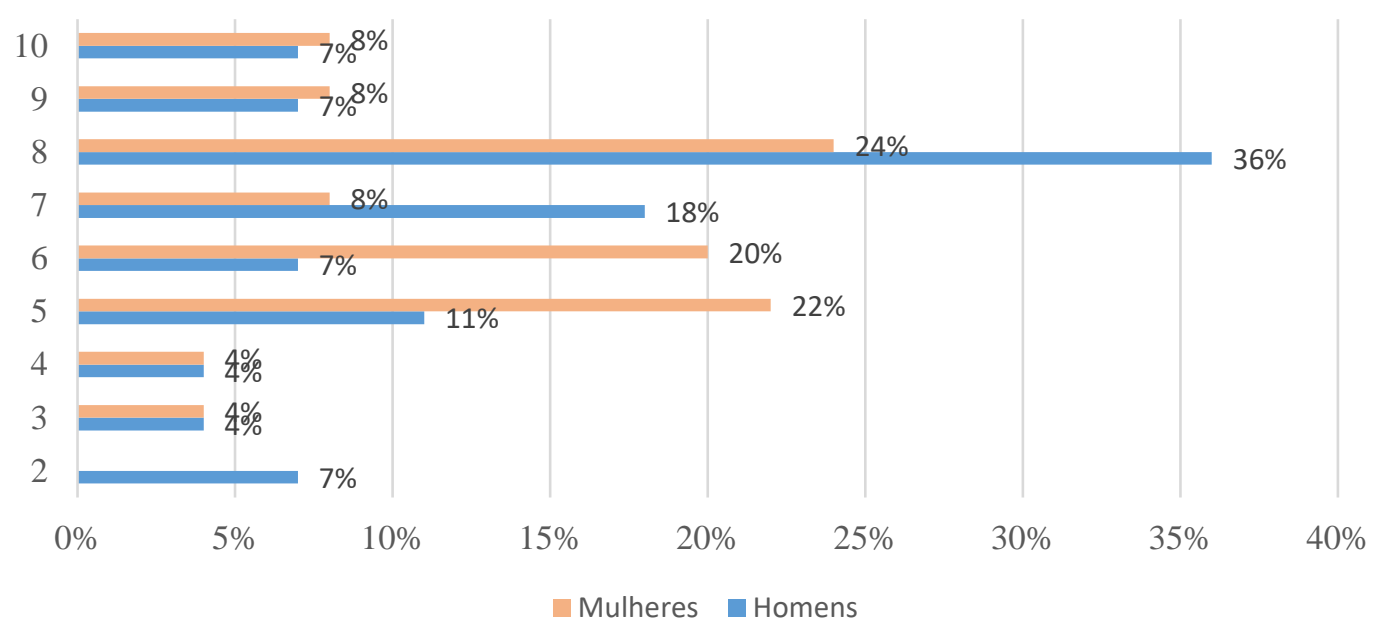

Fonte: Dados da Pesquisa (2016)

Para as pessoas que responderam que o som ambiente influenciava em sua decisão de compra, foi solicitado que estas apontassem o grau de influência desse fator sobre suas decisões. $54 \%$ dos homens deram um grau de importância entre 7 e 8 para o fator som ambiente, enquanto que $42 \%$ da mulheres deram um grau de importância entre 5 e 6, e $24 \%$ apontaram o grau 8 para o mesmo fator. Esses dados nos mostra que os homens acabam por serem mais influenciados do que as mulheres por um som ambiente durante as compras em supermercados.

Gráfico 3- Iluminação

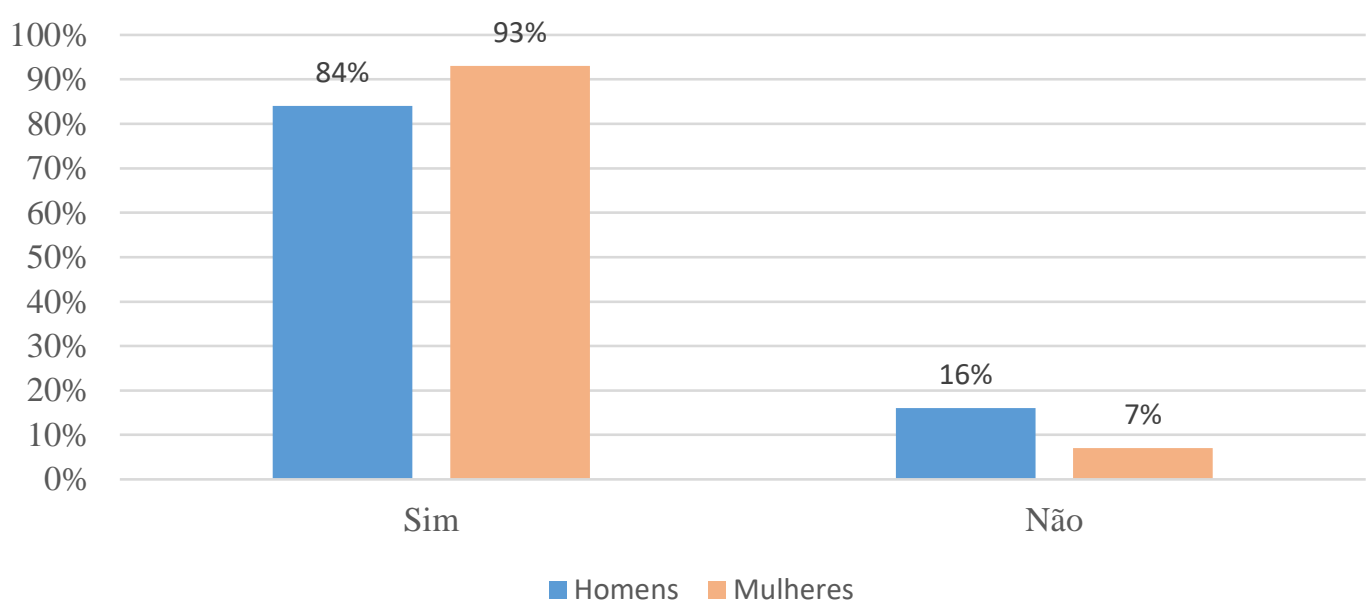

Fonte: Dados da Pesquisa (2016) 
De acordo com o gráfico 3, para $84 \%$ dos homens e $93 \%$ das mulheres entrevistados a iluminação do local tem influência sobre suas decisões de compra, e principalmente sobre sua escolha de onde comprarem. Apenas $16 \%$ dos homens e $7 \%$ das mulheres afirmaram o contrário. Estes dados mostram a importância de uma boa iluminação para criar um ambiente favorável as compras, o que Oliveira et al. (2007) apontam como sendo o foco do merchandising.

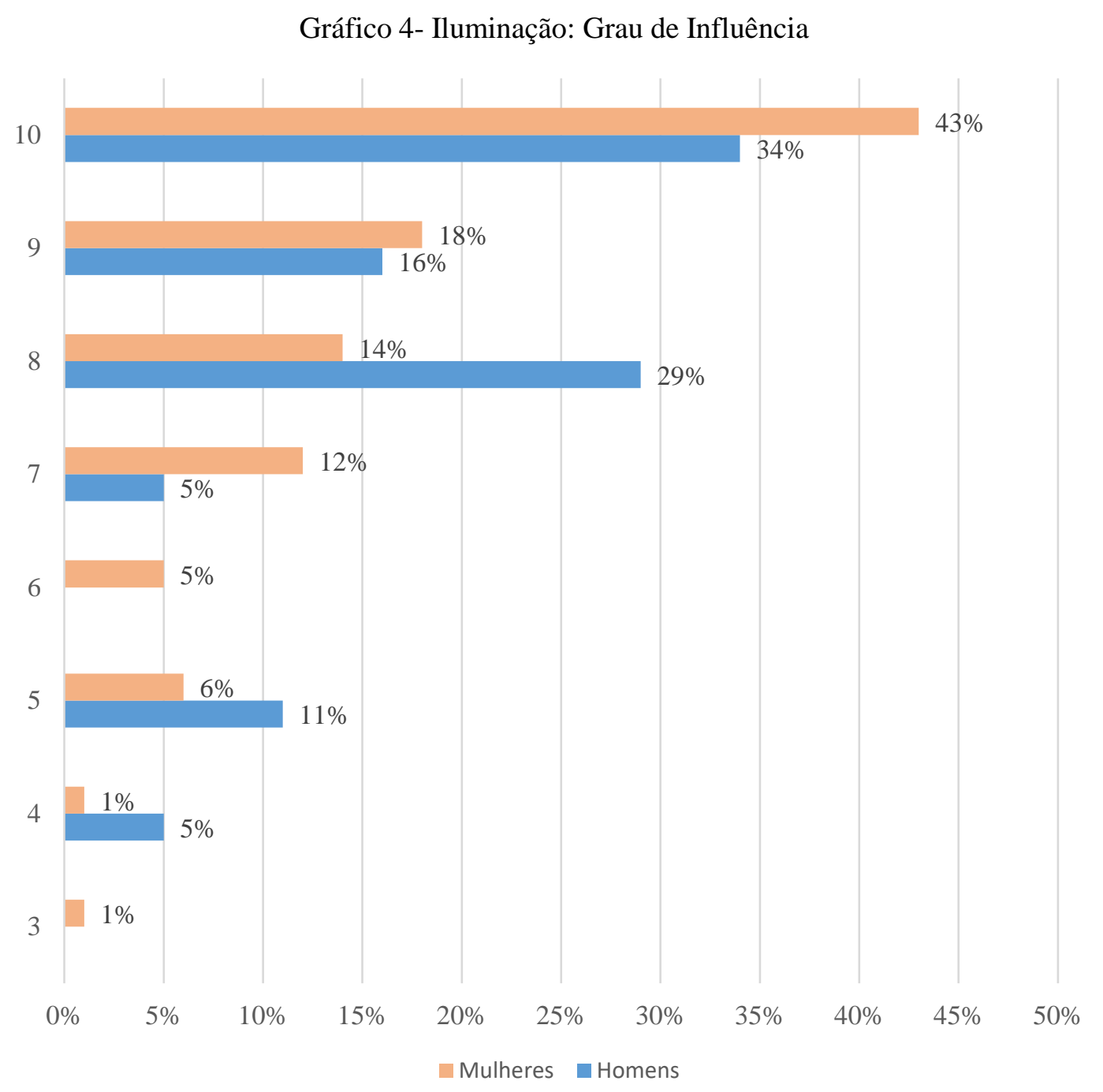

Fonte: Dados da Pesquisa (2016)

Para $75 \%$ das mulheres que responderam que a iluminação influencia nas suas decisões de compra, o grau de influência desse fator é entre 8 e 10, e $79 \%$ dos homens também apontaram o grau de influência entre 8 e 10. Com esse resultado nota-se a importância de uma boa 
iluminação para que seja criada uma atmosfera agradável às compras, uma vez que a iluminação adequada tem relação direta com diversas ferramentas do merchandising que foram apontadas por Las Casas (2009), como exposição e apresentação adequada dos produtos, visibilidade do estado do material no ponto de venda, e a visibilidade dos materiais de comunicação expostos nos pontos de venda.

Gráfico 5- Degustação

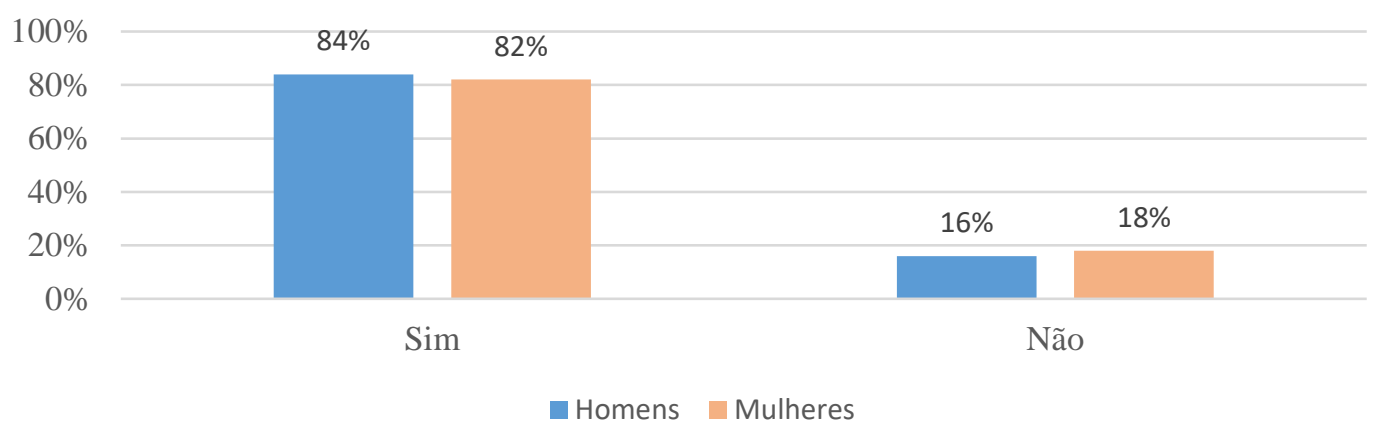

Fonte: Dados da Pesquisa (2016)

Apesar de ser um recurso pouco explorado em supermercados de pequeno e médio porte das cidades de interior, a degustação de produtos segundo $84 \%$ dos homens e $82 \%$ das mulheres, é um fator que influencia sobre suas decisões de compra. Apenas 16\% dos homens e $18 \%$ das mulheres entrevistados acreditam que esse fator não tem influência sobre suas decisões. Nota-se então que a degustação poderia ser uma ferramenta poderosa a ser aplicada nestes estabelecimentos, pois além de ser uma forma de se destacar dos concorrentes, permitiria a introdução de novos produtos e marcas, além de incentivar o consumo. 
Gráfico 6- Degustação: Grau de Influência

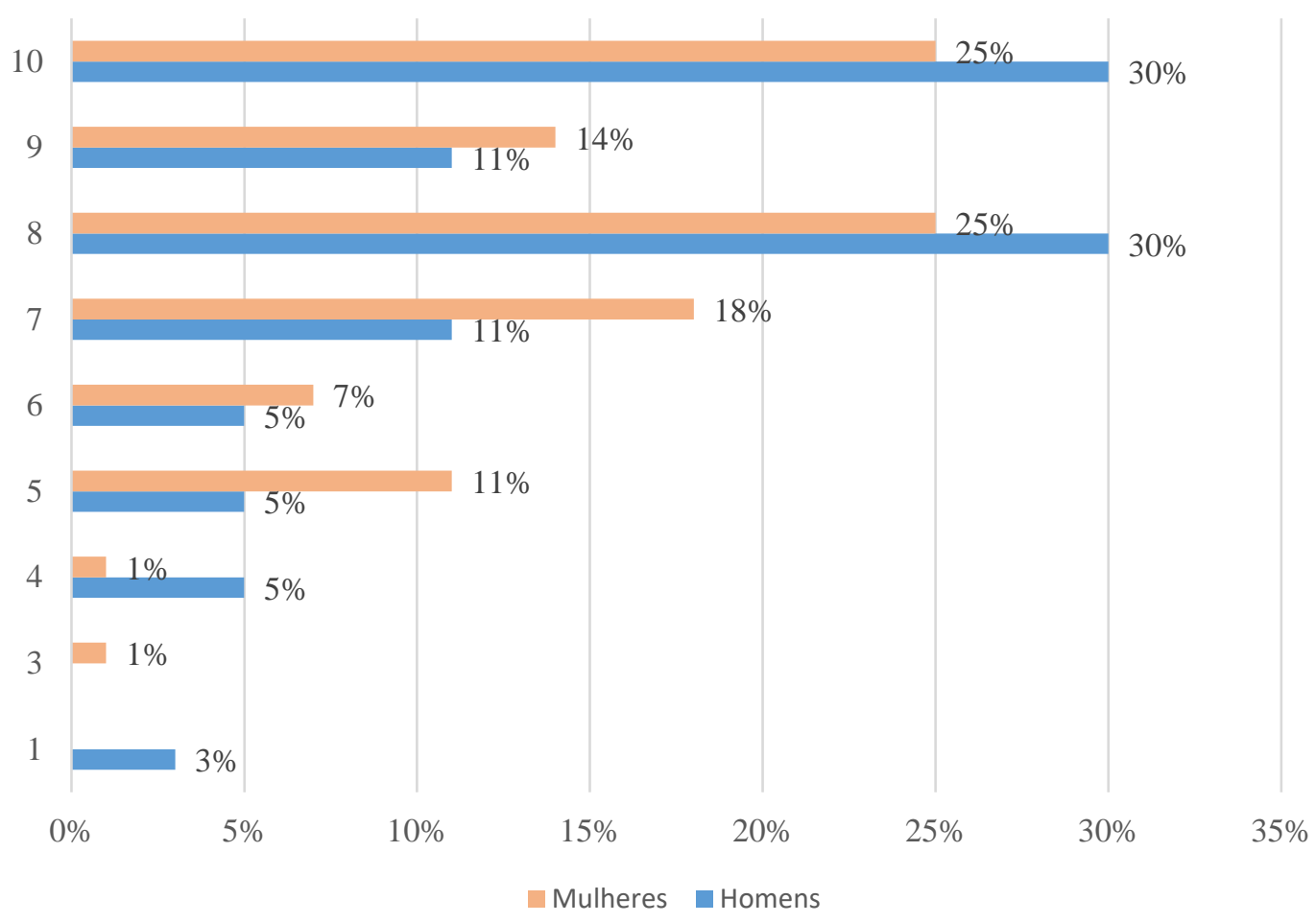

Fonte: Dados da Pesquisa (2016)

É interessante que se note que além de uma parcela muito significativa dos entrevistados terem respondido que a degustação influência sobre suas decisões de compra, nota-se também que o grau de influência é bastante elevado. Dos entrevistados que afirmaram que a degustação tem influência sobre suas escolhas, $71 \%$ dos homens e $64 \%$ das mulheres afirmaram que esse fator tem um grau de influência entre 8 e 10. Observa-se com isso que a degustação é um fator que vem sendo deixado de lado nas pequenas cidades, embora seja uma ferramenta poderosa para atrair novos clientes para marcas e produtos, podendo ter um impacto significativo sobre as vendas, e sobre a imagem que o consumidor tem de determinada marca. 
Gráfico 7- Limpeza

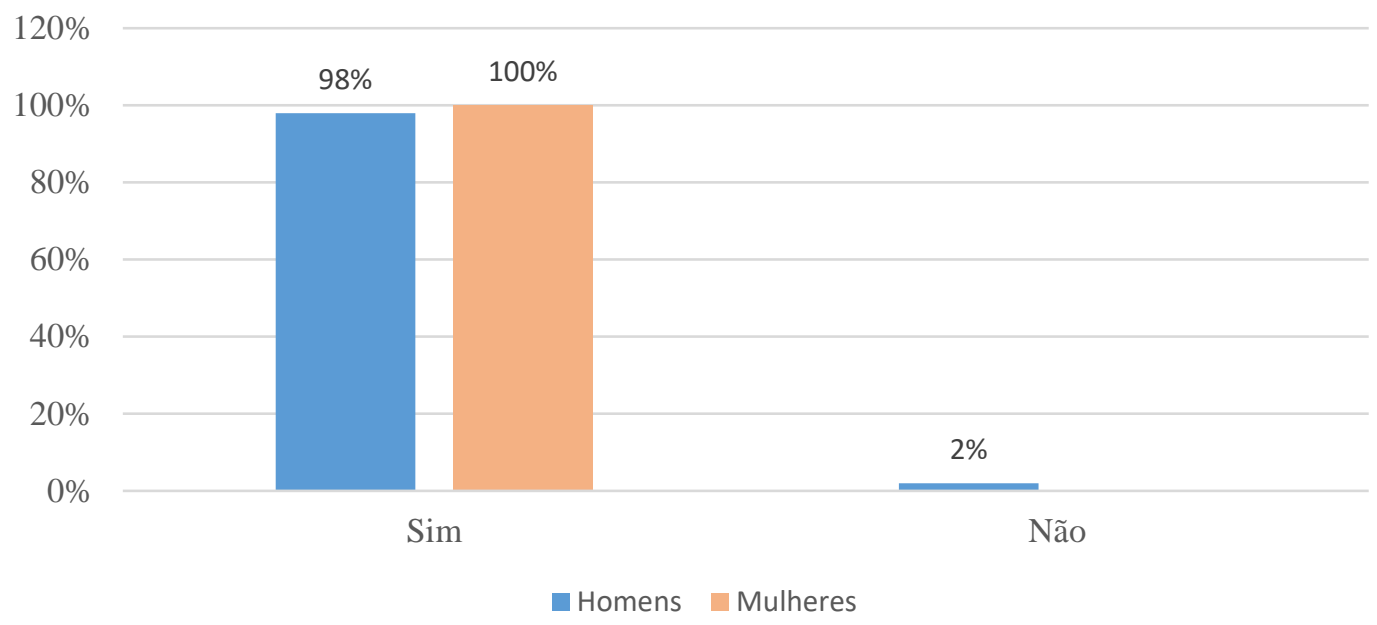

Fonte: Dados da Pesquisa (2016)

A limpeza é tida como o principal fator pelos entrevistados, de acordo com o gráfico acima, pode-se ver que $98 \%$ dos homens e $100 \%$ das mulheres afirmam que a limpeza do estabelecimento, das prateleiras e dos produtos expostos é um fator de suma importância para as suas decisões de compra. É interessante salientar que esse também é um fator muitas vezes esquecido pelos empresários que trabalham no ramo de supermercados nas pequenas cidades. 
Gráfico 8- Limpeza: Grau de Influência

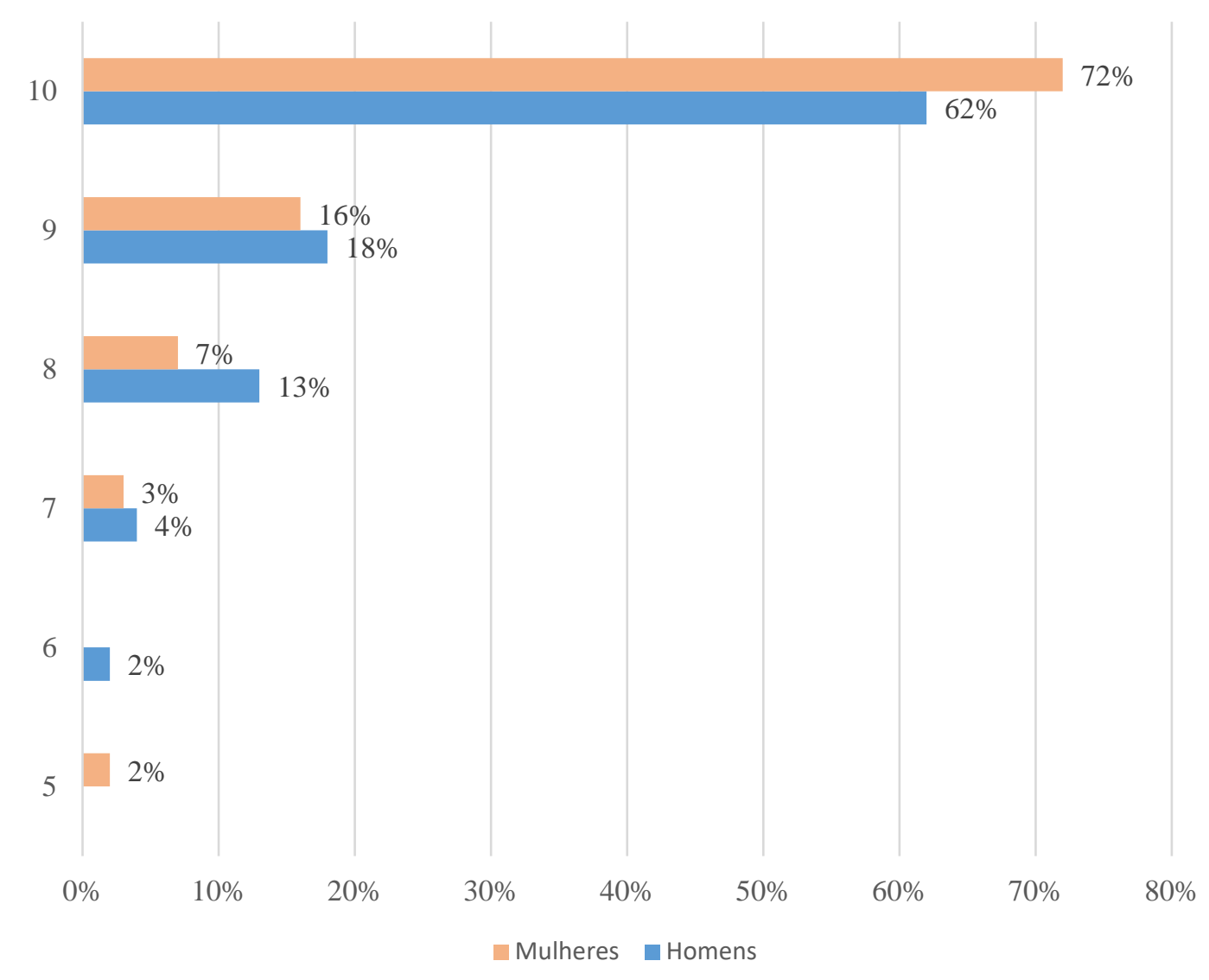

Fonte: Dados da Pesquisa (2016)

De acordo com o gráfico $8,80 \%$ dos homens e $88 \%$ das mulheres deram um grau de influência entre 9 e 10 para o fator limpeza. Fazendo desse fator, segundo a pesquisa realizada, o principal entre todos os que foram analisados. Apesar de ser um fator de custo relativamente baixo, e de se tratar também da responsabilidade dos comerciantes, é um fator que muitas vezes é negligenciado, mas que possui uma grande influência sobre os consumidores, a respeito principalmente da escolha do supermercado onde realizará suas compras frequentes. 


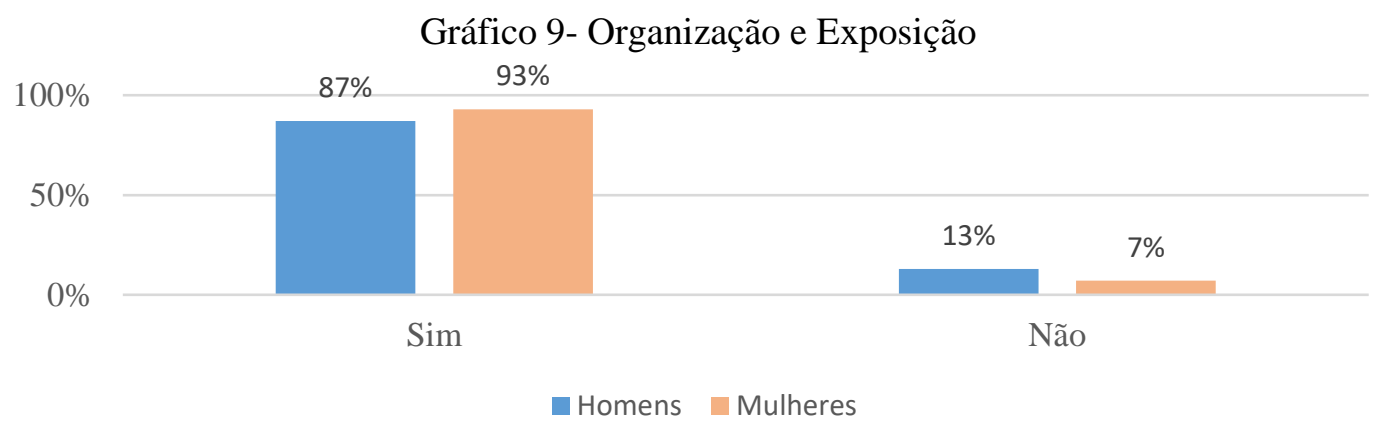

Fonte: Dados da Pesquisa (2016)

Segundo o gráfico 9, $87 \%$ dos homens e $93 \%$ das mulheres entrevistados afirmam que a organização e exposição dos produtos influencia nas suas tomadas de decisões. De acordo com essas pessoas, a forma como os produtos são expostos em prateleiras, ilhas e expositores próximos ao caixa por exemplo, acaba influenciando não só na escolha da marca, que segundo Bezerra; Viana (2013) geralmente acontece apenas no ponto de venda, como também incentivando a compra por impulso de variados produtos, o que para Blessa (2005) é o papel essencial do merchandising. 
Gráfico 10- Organização e Exposição: Grau de Influência

10

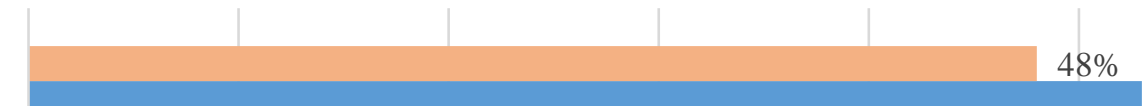

9

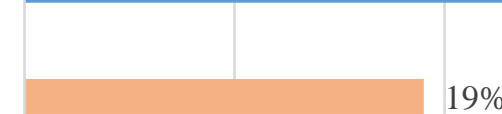

8

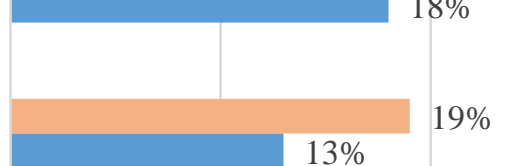

7

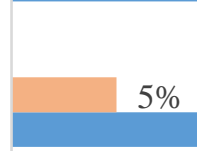

$13 \%$

6

$1 \%$

$3 \%$

5

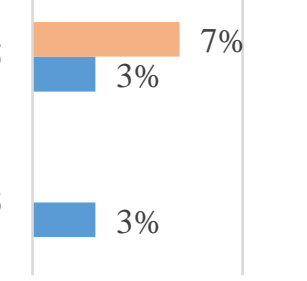

$0 \%$

$10 \%$

$10 \%$

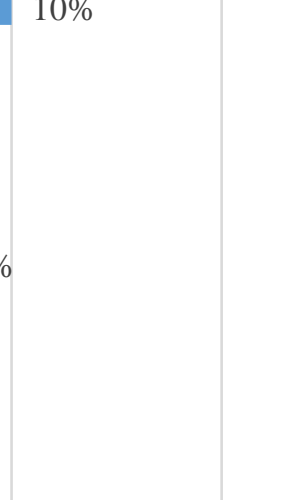

$20 \%$

$30 \%$

$40 \%$

$50 \%$

$60 \%$

Mulheres $\mathbf{n}$ Homens

Fonte: Dados da Pesquisa (2016)

Para $84 \%$ dos homens e $86 \%$ das mulheres que responderam que a organização e a exposição dos produtos influencia nas suas decisões de compra, o grau de influência desse fator é entre 8 e 10. De acordo com a pesquisa, este fator é tido como um dos mais importantes, principalmente nos casos em que os clientes têm pressa em realizar suas compras, fazendo com que a organização adequada dos produtos seja indispensável. 


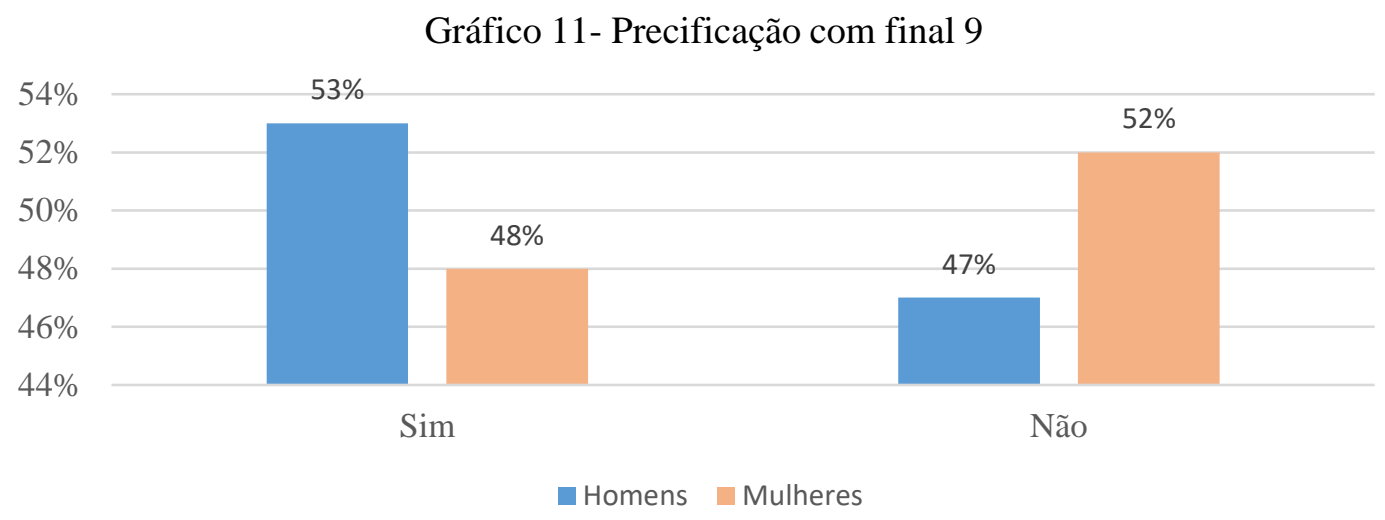

Fonte: Dados da Pesquisa (2016)

Sendo de acordo com a pesquisa realizada a ferramenta mais questionável do merchandising do ponto de vista dos consumidores, a precificação com final 9, amplamente utilizado no varejo, dividiu a opinião dos entrevistados. 53\% dos homens e $48 \%$ das mulheres afirmaram que a precificação com final 9 influencia nas decisões de compra, enquanto que $47 \%$ dos homens e $52 \%$ das mulheres dizem o contrário, afirmando que esse fator não tem influência sobre a decisão de compra.

Gráfico 12- Precificação com final 9: Grau de Influência

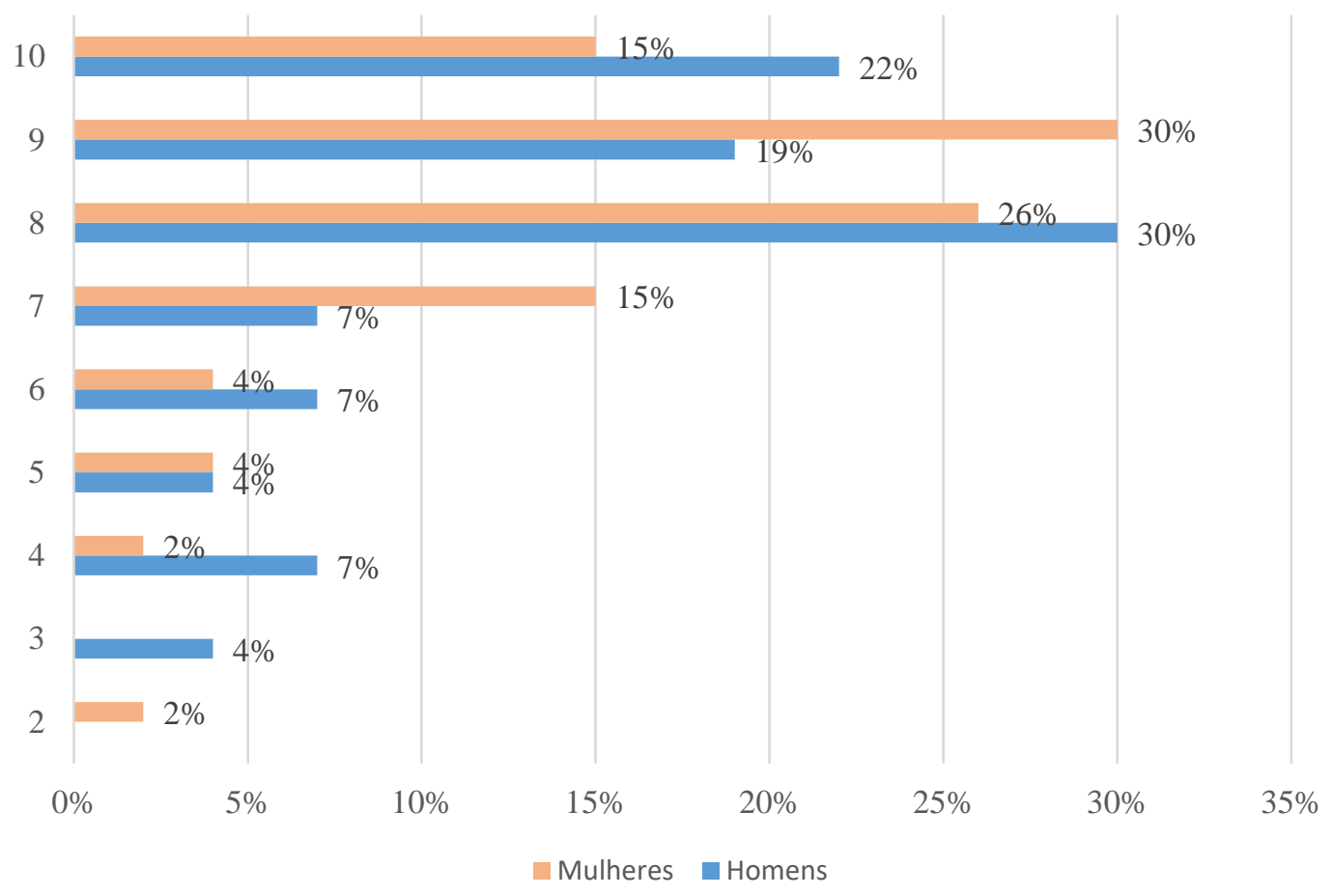

Fonte: Dados da Pesquisa (2016) 
Quando questionados sobre o grau de influência que eles acreditam que esse fator pode ter sobre as decisões de compra, $71 \%$ dos homens e $71 \%$ das mulheres afirmam que o grau de influência é entre 8 e 10. Apesar de ser a ferramenta do merchandising que mais dividiu opiniões na pesquisa realizada, autores como Memória (2010) afirmam que esse é um recurso de baixo custo que tem o potencial de chamar a atenção dos consumidores, despertando o desejo e impulso de compra.

\section{Considerações Finais}

Diante do crescimento constante da concorrência e da necessidade de se destacar em meio aos demais participantes do mercado, o merchandising tem se tornado cada dia mais importante no varejo, com destaque para o ramo de supermercados. Gerando com isso a necessidade do conhecimento das técnicas que envolvem o merchandising para que se faça uma implementação adequada das mesmas, tendo com isso um maior retorno sobre os investimentos realizados.

Os resultados da presente pesquisa mostram que as ferramentas do merchandising podem ser eficazes mesmo nas pequenas cidades, desde que implementadas de forma adequada, através de um planejamento eficiente de marketing voltado para o merchandising e para o próprio ponto de venda.

O merchandising e suas ferramentas devem ser implementadas para que possa atrair novos clientes, e para que produtos e marcas entrantes no mercado se tornem conhecidos e tenham a capacidade de sobreviver nesse mercado tão competitivo. No entanto, a pesquisa revela que apesar da eficiência do merchandising nas pequenas cidades, as suas ferramentas muitas vezes não são implementadas, e quando são, em diversos casos essa implementação é feita de forma inadequada, trazendo um resultado menor do que o esperado, desperdiçando assim parte significativa do potencial do merchandising.

A atual pesquisa revelou que o nível de influência nas decisões de compras dos clientes de supermercados, ocasionado pelas técnicas do merchandising aplicadas nos pontos de venda, mostra a eficácia dessas ferramentas, e o quanto elas podem ser decisivas para atrair e manter clientes. Faltam ainda investimento e treinamento adequado para que essas ferramentas possam 
ser aplicadas de forma mais efetiva e eficiente nas pequenas cidades, no entanto, mesmo sendo feito de forma muitas vezes precária, o merchandising já apresenta seus resultados e demonstra o seu potencial.

\section{Referências}

\section{ABRAS. RANKING ABRAS/SUPERHIPER 2016 MOSTRA OS GRANDES NÚMEROS} DO SETOR E AS MAIORES EMPRESAS. 29 mar. 2016. Disponível em: <http://www.abras.com.br/clipping.php?area=20\&clipping=55616>. Acesso em: 28 ago. 2016.

BEZERRA, G.J.; VIANA, J.J.S. A percepção do consumidor acerca das ações de merchandising: levantamento em u supermercado de Dourados/MS. Revista ADMpg Gestão Estratégica, Paraná, v.6, n.2. 2013. Disponível em: <http://www.admpg.com.br/revista2013_2/Artigos/11\%20$\% 20 \mathrm{~A} \% 20$ percepcao $\% 20 \mathrm{do} \% 20$ consumidor $\% 20$ acerca $\% 20$ das $\% 20$ acoes $\% 20 \mathrm{de} \% 20$ merchan dising\%20levantamento $\% 20 \mathrm{em} \% 20 \mathrm{um} \% 20$ supermercado\%20de $\% 20$ DouradosMS.pdf $>$. Acesso em: 04 maio. 2016.

BLESSA, Regina. Merchandising no ponto de venda. 4 ed. São Paulo: Atlas, 2008.

COSTA, A. R. F. et al. Encantos dos Elementos Constitutivos no Visual Merchandising das Vitrinas: Um Estudo de Caso Sobre a Percepção do Consumidor Natalense. Interface, Natal/RN, v.11, n.2 jul/dez 2014. Disponível em: <http://www.repositorio.ufop.br/handle/123456789/6870>. Acesso em: 16 maio. 2016.

FARIA, I.S.; FARIA, M. Pesquisa de Marketing: teoria e prática. São Paulo: M. Books do Brasil, 2009.

IBGE. Censo Demográfico 2010: resultados da amostra - características da população. Disponível em: $<$ http://cidades.ibge.gov.br/xtras/temas.php?lang=\&codmun=230160\&idtema=90\&search=ce ara|assare|censo-demografico-2010:-resultados-da-amostra-caracteristicas-da-populacao->. Acesso em: 09 set. 2016.

KANTAR IBOPE MEDIA. Meios de Comunicação 2015. Disponível em: $<$ https://www.kantaribopemedia.com/meios-de-comunicacao-2015/>. Acesso em: $11 \mathrm{fev}$. 2016.

KOTLER. Philip, KELLER, K.L. Administração de Marketing. $2^{\circ}$ ed. São Paulo: Pearson Hall, 2006.

LAS CASAS, A. L. Marketing de Serviços. 5. Ed. São Paulo: Atlas, 2007. 
LAS CASAS, A. L. Marketing: conceitos exercícios casos. 7. Ed. São Paulo: Atlas, 2006

LAS CASAS, A. L. Marketing: conceitos, exercícios, casos. 8 ed. São Paulo: Atlas, 2009.

MALHOTRA, N.K. Introdução à Pesquisa de Marketing. São Paulo: Prentice Hall, 2005.

MATTAR, F.N. Pesquisa de Marketing: metodologia, planejamento. 6 ed. São Paulo: Atlas, 2005 .

MEMÓRIA, P.R.F. O merchandising em ponto-de-venda como ferramenta de estratégia para vendas no varejo. Revista Eletrônica da Faculdade Metodista Granbery, Minas Gerais, n. 8, jan/jun. 2010. Disponível em: 〈http://re.granbery.edu.br/artigos/MzY1.pdf>. Acesso em: 04 maio. 2016.

OLIVEIRA, J; et al. Aplicação do merchandising como ferramenta de alavancagem das vendas no varejo de supermercados. 2007. Disponível em: $<$ http://intertemas.unitoledo.br/revista/index.php/Negocios/article/viewFile/555/578>. Acesso em: 16 maio. 2016.

ROCHA, A. CHRISTENSEN, C., Marketing, Teoria e Prática no Brasil. 2. Ed. São Paulo: Atlas, 1999.

SANTOS, Glauber Eduardo de Oliveira. Cálculo Amostral: calculadora on-line. Disponível em: <http://www.calculoamostral.vai.la>. Acesso em: 09 set. 2016.

XAVIER, B. D. J.; SILVA, R. P. A Influência da Embalagem sob a Ótica do Livro: Merchandising no Ponto de Venda. Maringá Management: Revista de Ciências Empresariais, v. 7, n.1, p. 16-21, jan./jun. 2010. Disponível em: <http://www.maringamanagement.com.br/novo/index.php/ojs/article/view/113/66>. Acesso em: 09 mar. 2016.

\section{Como citar este artigo (Formato ABNT):}

DIAS, Yasmin F.; OLIVEIRA, Gabriel J. A.; ALENCAR, Maria Patrícia de; TAVARES, Cristiano V. C. C. Análise da Eficácia da Ferramenta Merchandising: Um estudo com Consumidores de Supermercados na Cidade de Assaré. Id on Line Rev.Mult. Psic., 2018, vol.12, n.40, p.660-679. ISSN: 1981-1179.

Recebido: 07/05/2018

Aceito 11/05/2018 